\title{
The Case of $X$ and $Y$ Localization of Nucleolus Organizer Regions (NORs) in Tragulus javanicus (Cetartiodactyla, Mammalia)
}

\author{
Anastasia A. Proskuryakova 1,2,*(D), Anastasia I. Kulemzina ${ }^{1}$, Polina L. Perelman 1,2, \\ Natalia A. Serdukova ${ }^{1}$, Oliver A. Ryder ${ }^{3}$ and Alexander S. Graphodatsky ${ }^{1,2}$ iD \\ 1 Institute of Molecular and Cellular Biology, SB RAS, Lavrentiev ave 8/2, Novosibirsk 630090, Russia; \\ zakal@mcb.nsc.ru (A.I.K.); polina.perelman@gmail.com (P.L.P.); serd@mcb.nsc.ru (N.A.S.); \\ graf@mcb.nsc.ru (A.S.G.) \\ 2 Novosibirsk State University, Pirogova str. 1, Novosibirsk 630090, Russia \\ 3 San Diego Zoo Institute for Conservation Research, San Pasqual Valley Rd 15600, Escondido, CA 92027, \\ USA; oryder@sandiegozoo.org \\ * Correspondence: andrena@mcb.nsc.ru; Tel.: +7-960-799-5653
}

Received: 7 May 2018; Accepted: 18 June 2018; Published: 20 June 2018

\begin{abstract}
There are differences in number and localization of nucleolus organizer regions (NORs) in genomes. In mammalian genomes, NORs are located on autosomes, which are often situated on short arms of acrocentric chromosomes and more rarely in telomeric, pericentromeric, or interstitial regions. In this work, we report the unique case of active NORs located on gonosomes of a eutherian mammal, the Javan mouse-deer (Tragulus javanicus). We have investigated the position of NORs by FISH experiments with ribosomal DNA (rDNA) sequences (18S, 5.8S, and 28S) and show the presence of a single NOR site on the $X$ and $Y$ chromosomes. The NOR is localized interstitially on the $\mathrm{p}$-arm of the $\mathrm{X}$ chromosome in close proximity with prominent $\mathrm{C}$-positive heterochromatin blocks and in the pericentromeric area of mostly heterochromatic $\mathrm{Y}$. The NOR sites are active on both the $X$ and $Y$ chromosomes in the studied individual and surrounded by GC enriched heterochromatin. We hypothesize that the surrounding heterochromatin might have played a role in the transfer of NORs from autosomes to sex chromosomes during the karyotype evolution of the Javan mouse-deer.
\end{abstract}

Keywords: karyotype; chromosome evolution; genome; chevrotain; sex chromosomes; ribosomal DNA

\section{Introduction}

Nucleolus organizer regions (NORs) are crucial for the formation of the nucleolus and contain multiple copies of the ribosomal clusters interdigitated with non-transcribed intergenic spacers [1]. This ribosomal DNA encodes $45 \mathrm{~S}$ pre-rRNA. The post-transcription processing results in the production of three types of ribosomal RNA (18S, 5.8S, and 28S) [2]. The ribosomal RNA is further processed and packed into large (5.8S, 28S, and separate non-nucleolus $5 \mathrm{~S}$ rDNA) and small (18S) subunits of the ribosome, that are responsible for RNA translation and thus critical for cellular functions [1]. These ribosomal DNA sequences exhibit a high degree of conservation across animals. In contrast with sequence conservation, rDNA clusters are characterized by variation in copy-number [3], rDNA content of NORs between individuals [4], between the cells of one individual [5], and variable localization in different animal species [6,7]. The variation in the number of transcriptionally active NORs can occur even between the cells and tissues of one individual [8]. NORs are predominantly located in telomere regions, colocalizing with telomeric repeats [9], in the short arms or near centromeric regions of acrocentric chromosomes [10-13] and more rarely interstitially [14,15]. The quantity of ribosomal genes at telomeric sites is variable $[16,17]$. In most mammalian species, NORs are situated 
on autosomes. However, localization of NORs on sex chromosomes is not uncommon in fish [18-21] and insects [12,14].

There is a problem in mammals with a localization of NORs on sex chromosomes, due to heterogametic sex and dosage compensation, and only a few cases have been described. In some marsupials, the NOR located on the $X$ seems to escape $X$-inactivation [22,23]. Thus, specific mechanisms exist for regulating NOR expression in these cases. The localization of a NOR on the $X$ was shown in Seba's short-tailed bat (Carollia perspicillata) [24]. An inactive NOR was described for Lemniscomys barbarus (Muridae, Rodentia) $\mathrm{X}$ and $\mathrm{Y}$ chromosomes and its participation in the sex chromosome recombination process was suggested [25]. Thus, localization of rDNA clusters on sex chromosomes in mammals is extremely rare.

The mammalian order Cetartiodactyla provides a few examples of sex chromosome localization of NORs. In the Indian muntjac (Muntiacus muntjac) (Cervidae) NORs are localized on the sex chromosomes due to the translocation of a NOR-carrying autosome onto the $\mathrm{X}$ chromosome $[6,26]$. The male nilgai (Boselaphus tragocamelus) (Bovidae) is another example of sex-chromosome localization of a NOR. However, there is a complex sex chromosome structure consisting of a translocated autosome 14 onto the $X$ and $Y$, and the NOR is located on the 14 part of compound 14;X but not on 14;Y [15]. We have not found in literature other examples of sex chromosome localization of NORs in Cetartiodactyla.

In this study, we describe the sex chromosome localization of a NOR in a Javan mouse-deer karyotype (Tragulidae), provide its molecular cytogenetic characterization by localization of ribosomal genes, and investigate the activity of these NORs and surrounding regions.

\section{Materials and Methods}

\subsection{Cell Culture and Chromosome Preparation}

Metaphase chromosomes were obtained from cultured fibroblast cell line. Cells were incubated at $37^{\circ} \mathrm{C}$ and $5 \% \mathrm{CO}_{2}$ in $\alpha \mathrm{MEM}$ (Gibco, Paisley, Scotland, UK), supplemented with $15 \%$ fetal bovine serum (Gibco), 5\% AmnioMAX-II (Gibco) and antibiotics (ampicillin $100 \mu \mathrm{g} / \mathrm{mL}$, penicillin $100 \mu \mathrm{g} / \mathrm{mL}$ ). Metaphases were obtained by adding colcemid $(0.01 \mu \mathrm{g} / \mathrm{mL})$ and $\mathrm{EtBr}(0.05 \mu \mathrm{g} / \mathrm{mL})$ to actively dividing culture [27]. Hypotonic treatment was performed with $\mathrm{KCl}(33 \mathrm{mM})$ and trisodium citrate $(7.7 \mathrm{mM})$ for $20 \mathrm{~min}$ at $37^{\circ} \mathrm{C}$ and followed by fixation with 3:1 methanol-glacial acetic acid fixative. Metaphase chromosome preparations were made from fixed cultures, as described previously [28].

\subsection{Nucleolus Organizer Regions Detection}

To reveal the localization of NORs, plasmid DNA (pHr13 [29]), containing human partial 18S, full 5.8S, part of the $28 \mathrm{~S}$ ribosomal genes and two internal transcribed spacers, was amplified with a GenomePlex Whole Genome Amplification kit (Sigma-Aldrich Co., St. Louis, MO, USA) and labeled with biotin (Roche, Basel, Switzerland) by GenomePlex WGA Reamplification Kit (Sigma-Aldrich Co., St. Louis, MO, USA). The banding pattern obtained by standard trypsin/Giemsa (GTG) treatment of metaphase chromosomes was photographed prior to fluorescence in situ hybridization (FISH) [30]. FISH was performed as described by F. Yang and A. Graphodatsky [28].

\subsection{Silver Staining of Metaphase Chromosome}

To reveal active NORs the silver staining of metaphase chromosome with $\mathrm{AgNO}_{3}$ was performed according to [31].

\subsection{The Combined Method of Heterogeneous Heterochromatin Detection (CDAG)}

Heterochromatin analysis was performed by the Combined Method of Heterogeneous Heterochromatin Detection (CDAG) method [32]. AT- and GC-enriched repetitive sequences were detected by DAPI (4'-6-diamidino-2-phenylindol) and CMA3 (chromomycin A3) fluorescent dyes. 
All images were captured and processed using Video-test 2.0 Image Analysis System and a Baumer Optronics CCD Camera mounted on an Olympus BX53 microscope (Olympus, Shinjuku, Japan).

\section{Results}

In order to obtain data about active and silent NORs, we have performed $\mathrm{AgNO}_{3}$ staining and localized rDNA sequences (18S, $5.8 \mathrm{~S}$ and $28 \mathrm{~S}$, which represent main part of the ribosomal cluster) by FISH (Figure 1(1)), respectively. We have identified the only pair of active NORs (Figure 1(2)) on sex chromosomes. Interestingly this NOR is located not only on the $\mathrm{X}$ but also on the subtelocentric $\mathrm{Y}$ chromosome. The NOR on the $\mathrm{X}$ chromosome is larger and positioned in the middle of the $\mathrm{p}$-arm at a secondary constriction. On the $\mathrm{Y}$ chromosome, it is located close to the centromere.

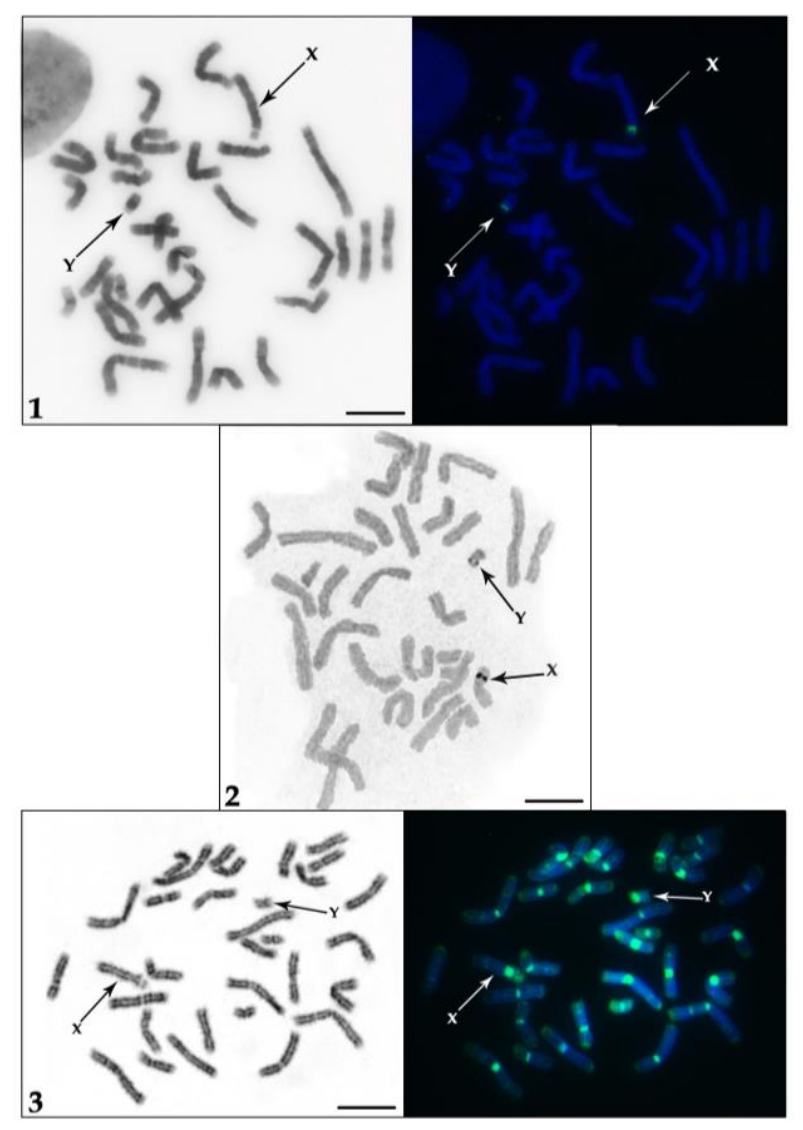

Figure 1. Metaphase chromosomes of Tragulus javanicus: (1) Localization of 18S, 5.8S, and 28S ribosomal DNA (rDNA): inverted DAPI (4'-6-diamidino-2-phenylindol)-staining (left) and labeled DNA sequences (right), (2) $\mathrm{AgNO}_{3}$ staining of the Nucleolus organizer regions (NORs), (3) CDAG staining: GTG-banding (left) and CMA3/DAPI-staining (right). Scale bar $=10 \mu \mathrm{m}$.

To investigate chromosomal regions of the NORs and to describe the adjacent heterochromatin we performed consecutive differential staining: a GTG-banding to identify chromosomes followed by CDAG-staining to uncover AT- and GC-rich heterochromatin (Figure 1(3)). We observed that pericentromeric heterochromatin on the $\mathrm{X}$ and the $\mathrm{Y}$ is comprised of both AT- and GC-rich sequences. The interstitial heterochromatic block on the $X$ chromosome is composed of GC-rich sequences. On the $X$ there are two prominent C-positive bands [33] on both sides of the NOR-the proximal one is GC-rich and the distal one is slightly GC-enriched. The adjacent heterochromatin band on the q-arm of the $Y$ is also GC-rich. Notably, both T. javanicus NORs are CMA3 positive proving support that these regions are enriched in GC sequences [29]. 


\section{Discussion}

Nucleolus organizer regions play an important role in genome functioning and are prominent cytogenetic markers. Among mammals, there are just a few cases of the NOR localization on sex chromosomes $[6,15,26,34]$. We have found a unique case of NOR localization on both X and Y chromosomes in the Javan mouse-deer. This case shows the importance of the use of multiple chromosome staining techniques while describing karyotype of species to reveal features of genome organization on chromosome level.

The Javan mouse-deer possesses a karyotype with $2 \mathrm{n}=32, \mathrm{NF}=64$ with all bi-armed chromosomes. G-, C- and Q-banded karyotypes of Javan mouse-deer were described by D. S. Gallagher with co-authors [33]. C-banding revealed prominent heterochromatin blocks covering almost the entire $\mathrm{p}$-arm of the $X$ and proximal part of the q-arm and one interstitial block in the distal part of the q-arm (Figure 2). The $\mathrm{Y}$ chromosome is mostly composed of a large heterochromatin block. The probe containing $18 \mathrm{~S}+5.8 \mathrm{~S}+28 \mathrm{~S}$ rDNA covers most of the active ribosomal cluster. Multiple copies of this cluster form the nucleolus organizer region demonstrate a distinct localization of NORs near the centromere region on the $X$ and $Y$ chromosomes in the middle of large heterochromatic blocks. The CDAG staining indicates that the NORs in T. javanicus are located in the proximity of GC-rich heterochromatin region.
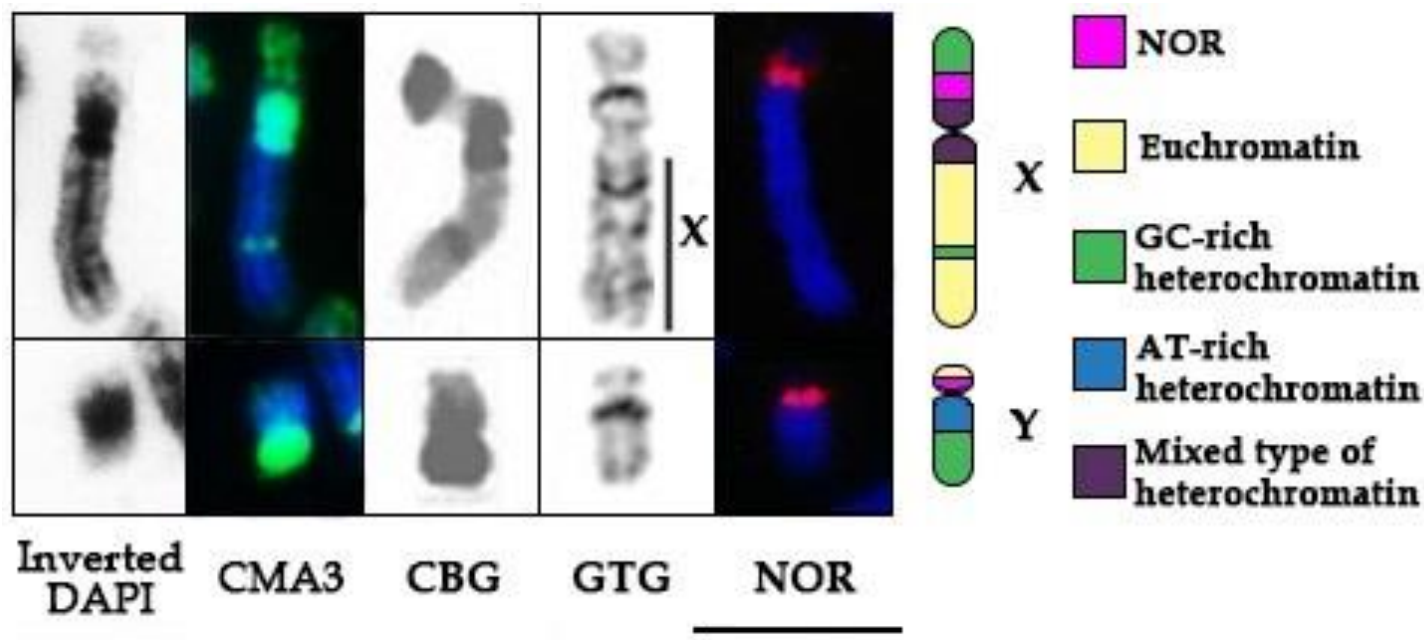

Figure 2. Differential staining of sex chromosomes $(\mathrm{X}, \mathrm{Y})$ of Javan mouse-deer: Inverted DAPI (AT-rich heterochromatin) CDAG-staining; CMA3 (GC-rich heterochromatin) CDAG-staining; CBG (CBG-C-bands by Barium hydroxide using Giemsa) [33]; GTG (G-bands by Trypsin using Giemsa) [35]; DAPI-staining and FISH localization of $18 \mathrm{~S}, 5,8 \mathrm{~S}$ and $28 \mathrm{~S}$ rDNA probe. Scale bar $=10 \mu \mathrm{m}$.

It remains unexplained how the NOR that is typically located on the autosomes in Cetartiodactyla was translocated onto the sex chromosomes. There are data about NOR variation in the number and chromosomal location in closely related species, suggesting that rDNA clusters are highly mobile components of the genome [4,36]. In species related to Javan mouse deer, such as gray whale [13] and giraffe [37] NORs are situated on non-homologous chromosomes representing different syntenic groups. Such interspecies lability of NORs is generated either by chromosomal rearrangements or transposition events [38]. Possibly, the high transposition rates of NORs are observed because of transposons inserted in the rDNA clusters, as it has been documented in plants [39] and into intergenic spacer repeats in the house mouse [40]. However, the transposition of NORs from autosome to sex chromosome may also be due to the translocation of an ancestral autosome carrying NORs. The rare cases of the addition of autosomal material to the sex chromosomes have been reported previously [41], including one with the NOR translocation in the nilgai bull [15]. The clustered NOR structure also might contribute to its instability, facilitated by an illegitimate recombination between non-homologous 
chromosomes. It results in variation of the number of sequences per NOR and the localization on various chromosomes even in closely related species [7].

The Javan mouse-deer X chromosome [42] and karyotype [35] were formed as a result of many changes during cetartiodactyl genome evolution. Telomeres and centromeres in the Javan mouse-deer karyotype have prominent C-banded regions as well as interstitial C-bands. Ribosomal gene sequences might migrate with the surrounding heterochromatin onto sex chromosomes during genome rearrangements, particularly to the $\mathrm{X}$ chromosome, followed by subsequent fixation. It may also be possible that the adjacent abundant heterochromatin facilitated NOR transfer during recombination [43]. The NOR in a species of May bug (Melolontha melolontha) is surrounded by heterochromatin and exhibits the main features of fragile sites such as gaps, deletions and chromatid exchanges [14]. The NORs in Tragulus javanicus is also surrounded by heterochromatin and may be prone to fragile site behavior.

It also remains unknown whether this positioning of the NOR provided a selective advantage for the species. In meiosis, there is a recombination block in NORs, heterochromatic, and highly repeated sequences [25,44]. But in Lemniscomys barbarus (Muridae, Rodentia) [25] the NOR sequences translocated onto sex chromosomes promoted the increase in the recombination region. In this species, $\mathrm{X}-\mathrm{Y}$ pairing proceeds beyond the pseudoautosomal region colocalizing with the silent ribosomal sequences and heterochromatin [25]. Such an increase of the recombination region may lead to new genetic variants providing selective advantages, leading to a fixation of the NORs on the sex chromosomes. It would be useful to study the $X-Y$ recombination region in Javan mouse-deer because the NORs sequences are adjacent to heterochromatic elements situated in these regions, like in L. barbarus [25].

It would be interesting to investigate whether the NOR is adjacent to the pseudoautosomal region (PAR) on both the $\mathrm{X}$ and the $\mathrm{Y}$ chromosome in Javan mouse-deer, as well as to inspect the NOR localization in other chevrotain species. Unfortunately, there is no whole genome sequence data or chromosome assembly for Tragulidae species available to design a Y chromosome PAR probe. Comparative cattle BAC mapping data indicate that PAR in Tragulus is likely to be situated on the q-arm of X chromosome immediately distal to the heterochromatic block [41]. Chromosome painting indicates that the euchromatin portion occupies only the distal part of the q-arm of the X [42], so it is possible that the NOR and the pseudoautosomal region are separated by a large heterochromatin block on the X. However, the location of the PAR on the T. javanicus $Y$ chromosome is unknown. It is possible that the NOR and the PAR on the Javan mouse-deer $Y$ chromosome are positioned similarly to the $\operatorname{dog} \mathrm{Y}$ where the PAR and the NOR are separated by the centromeric heterochromatin block [45], but we cannot exclude $\mathrm{p}$-arm localization of the PAR.

The sex chromosome (both the $\mathrm{X}$ and the $\mathrm{Y}$ ) localization of the single active NOR surrounded by GC-rich heterochromatin in Javan mouse-deer represents a unique case among mammals and warrants further investigation of the link between ribosomal clusters and heterochromatin and also of the poorly understood role of NOR variation in karyotype and species evolution processes.

Author Contributions: A.S.G. and A.I.K. conceived and designed the experiments; A.I.K. prepared probes for experiments; A.A.P. performed the experiments and analyzed the data; N.A.S. isolated plasmid DNA; O.A.R. provided cell lines; P.L.P. prepared the suspension of metaphase chromosome; A.A.P., P.L.P., and O.A.R. wrote the paper. All authors read and approved the final paper.

Funding: The work was supported by the Russian Science Foundation (RSF, 16-14-10009).

Acknowledgments: We kindly acknowledge Julia Butakova for supporting works in the Laboratory of Mammalian Cytogenetics, IMCB, Novosibirsk, Russia. We sincerely acknowledge N. Lemskaya (Laboratory of Mammalian Cytogenetics, IMCB, Novosibirsk, Russia) for sharing the CDAG-protocol. We would like to acknowledge two anonymous reviewers for their critical comments.

Conflicts of Interest: The authors declare no conflict of interest. 


\section{References}

1. Olson, M.O.J. The Nucleolus; Springer: Berlin, Germany, 2011; ISBN 978-1-4614-0514-6.

2. Wilson, G.N. The structure and organization of human ribosomal genes. Cell Nucl. 1982, 10, 289-318.

3. Winking, H.; Nielsen, K.; Gropp, A. Variable positions of NORs in Mus musculus. Cytogenet. Genome Res. 1980, 26, 158-164. [CrossRef] [PubMed]

4. Britton-Davidian, J.; Cazaux, B.; Catalan, J. Chromosomal dynamics of nucleolar organizer regions (NORs) in the house mouse: micro-evolutionary insights. Heredity 2012, 108, 68-74. [CrossRef] [PubMed]

5. Stults, D.M.; Killen, M.W.; Williamson, E.P.; Hourigan, J.S.; Vargas, H.D.; Arnold, S.M.; Moscow, J.A.; Pierce, A.J. Human rRNA gene clusters are recombinational hotspots in cancer. Cancer Res. 2009, 69, 9096-9104. [CrossRef] [PubMed]

6. Hsu, T.C.; Spirito, S.E.; Pardue, M.L. Distribution of 18+ 28 S ribosomal genes in mammalian genomes. Chromosoma 1975, 53, 25-36. [CrossRef] [PubMed]

7. Gerbault-Seureau, M.; Cacheux, L.; Dutrillaux, B. The Relationship between the (In-) Stability of NORs and their chromosomal location: The example of Cercopithecidae and a short review of other primates. Cytogenet. Genome Res. 2017, 153, 138-146. [CrossRef] [PubMed]

8. Guillén, A.K.Z.; Hirai, Y.; Tanoue, T.; Hirai, H. Transcriptional repression mechanisms of nucleolus organizer regions (NORs) in humans and chimpanzees. Chromosome Res. 2004, 12, 225-237. [CrossRef] [PubMed]

9. Hall, K.J.; Parker, J.S. Stable chromosome fission associated with rDNA mobility. Chromosome Res. 1995, 3 , 417-422. [CrossRef] [PubMed]

10. Henderson, A.S.; Warburton, D.; Atwood, K.C. Location of ribosomal DNA in the human chromosome complement. Proc. Natl. Acad. Sci. USA 1972, 69, 3394-3398. [CrossRef] [PubMed]

11. Henderson, A.S.; Atwood, K.C.; Warburton, D. Chromosomal distribution of rDNA in Pan paniscus, Gorilla gorilla beringei, and Symphalangus syndactylus: Comparison to related primates. Chromosoma 1976, 59, 147-155. [CrossRef] [PubMed]

12. Cabrero, J.; Camacho, J.P.M. Location and expression of ribosomal RNA genes in grasshoppers: Abundance of silent and cryptic loci. Chromosome Res. 2008, 16, 595-607. [CrossRef] [PubMed]

13. Kulemzina, A.I.; Proskuryakova, A.A.; Beklemisheva, V.R.; Lemskaya, N.A.; Perelman, P.L.; Graphodatsky, A.S. Comparative chromosome map and heterochromatin features of the gray whale karyotype (Cetacea). Cytogenet. Genome Res. 2016, 148, 25-34. [CrossRef] [PubMed]

14. Dutrillaux, A.-M.; Carton, B.; Cacheux, L.; Dutrillaux, B. Interstitial NORs, Fragile sites, and chromosome evolution: a not so simple relationship-the example of Melolontha melolontha and genus Protaetia (Coleoptera: Scarabaeidae). Cytogenet. Genome Res. 2016, 149, 304-311. [CrossRef] [PubMed]

15. Gallagher, D.S.; Davis, S.K.; De Donato, M.; Burzlaff, J.D.; Womack, J.E.; Taylor, J.F.; Kumamoto, A.T. A karyotypic analysis of nilgai, Boselaphus tragocamelus (Artiodactyla: Bovidae). Chromosome Res. 1998, 6, 505-514. [CrossRef] [PubMed]

16. Volleth, M. Differences in the location of nucleolus organizer regions in European vespertilionid bats. Cytogenet. Genome Res. 1987, 44, 186-197. [CrossRef] [PubMed]

17. Nirchio, M.; Oliveira, C.; Ferreira, I.A.; Granado, A.; Ron, E. Extensive polymorphism and chromosomal characteristics of ribosomal DNA in the characid fish Triportheus venezuelensis (Characiformes, Characidae). Genet. Mol. Biol. 2007, 30, 25-30. [CrossRef]

18. Scacchetti, P.C.; Utsunomia, R.; Pansonato-Alves, J.C.; da Costa Silva, G.J.; Vicari, M.R.; Artoni, R.F.; Oliveira, C.; Foresti, F. Repetitive DNA sequences and evolution of ZZ/ZW sex chromosomes in Characidium (Teleostei: Characiformes). PLoS ONE 2015, 10, e0137231. [CrossRef] [PubMed]

19. Machado, T.C.; Pansonato-Alves, J.C.; Pucci, M.B.; Nogaroto, V.; Almeida, M.C.; Oliveira, C.; Foresti, F.; Bertollo, L.A.; Moreira-Filho, O.; Artoni, R.F.; et al. Chromosomal painting and ZW sex chromosomes differentiation in Characidium (Characiformes, Crenuchidae). BMC Genet. 2011, 12, 65. [CrossRef] [PubMed]

20. Schartl, M.; Schmid, M.; Nanda, I. Dynamics of vertebrate sex chromosome evolution: from equal size to giants and dwarfs. Chromosoma 2016, 125, 553-571. [CrossRef] [PubMed]

21. Yano, C.F.; Bertollo, L.A.C.; Molina, W.F.; Liehr, T.; de Bello Cioffi, M. Genomic organization of repetitive DNAs and its implications for male karyotype and the neo-Y chromosome differentiation in Erythrinus erythrinus (Characiformes, Erythrinidae). Comp. Cytogenet. 2014, 8, 139. [CrossRef] [PubMed] 
22. Cooper, D.W.; Johnston, P.G.; Watson, J.M.; Graves, J.A.M. X-inactivation in marsupials and monotremes. In Seminars in Developmental Biology; Elsevier: Amsterdam, The Netherlands, 1993; Volume 4, pp. 117-128.

23. Merry, D.E.; Pathak, S.; VandeBerg, J.L. Differential NOR activities in somatic and germ cells of Monodelphis domestica (Marsupialia, Mammalia). Cytogenet. Genome Res. 1983, 35, 244-251. [CrossRef] [PubMed]

24. Goodpasture, C.; Bloom, S.E. Visualization of nucleolar organizer regions in mammalian chromosomes using silver staining. Chromosoma 1975, 53, 37-50. [CrossRef] [PubMed]

25. Stitou, S.; Jimenez, R.; De La Guardia, R.D.; Burgos, M. Sex-chromosome pairing through heterochromatin in the African rodent Lemniscomys barbarus (Rodentia, Muridae). A synaptonemal complex study. Chromosome Res. 2000, 8, 277-283. [CrossRef] [PubMed]

26. Pardue, M.L.; Hsu, T.C. Locations of $18 \mathrm{~S}$ and $28 \mathrm{~S}$ ribosomal genes on the chromosomes of the Indian muntjac. J. Cell Biol. 1975, 64, 251-254. [CrossRef] [PubMed]

27. Stanyon, R.; Galleni, L. A rapid fibroblast culture technique for high resolution karyotypes. Ital. J. Zool. 1991, 58, 81-83. [CrossRef]

28. Yang, F.; Graphodatsky, A.S. Animal probes and ZOO-FISH. In Fluorescence In Situ Hybridization (FISH); T. Liehr: Berlin, Germany, 2017; pp. 323-346.

29. Maden, B.E.H.; Dent, C.L.; Farrell, T.E.; Garde, J.; McCALLUM, F.S.; Wakeman, J.A. Clones of human ribosomal DNA containing the complete 18 S-rRNA and 28 S-rRNA genes. Characterization, a detailed map of the human ribosomal transcription unit and diversity among clones. Biochem. J. 1987, 246, 519-527. [CrossRef] [PubMed]

30. Seabright, M. A rapid banding technique for human chromosomes. Lancet 1971, 298, 971-972. [CrossRef]

31. Graphodatsky, A.S.; Radjabli, S.I. Chromosomes of Agricultural and Laboratory Animals. Atlas; Nauka: Novosibirsk, Russia, 1988.

32. Lemskaya, N.A.; Kulemzina, A.I.; Beklemisheva, V.R.; Biltueva, L.S.; Proskuryakova, A.A.; Perelman, P.L.; Graphodatsky, A.S. The combined method of heterogeneous heterochromatin detection (CDAG) in different mammalian species. Chromosoma 2018.

33. Gallagher, D.S.; Houck, M.L.; Ryan, A.M.; Womack, J.E.; Kumamoto, A.T. A karyotypic analysis of the lesser Malay chevrotain, Tragulus javanicus (Artiodactyla: Tragulidae). Chromosome Res. 1996, 4, 545-551. [CrossRef] [PubMed]

34. Mäkinen, A.; Zijlstra, C.; de Haan, N.A.; Mellink, C.H.M.; Bosma, A.A. Localization of 18S+28S and 5S ribosomal RNA genes in the dog by fluorescence in situ hybridization. Cytogenet. Genome Res. 1997, 78, 231-235. [CrossRef]

35. Kulemzina, A.I.; Yang, F.; Trifonov, V.A.; Ryder, O.A.; Ferguson-Smith, M.A.; Graphodatsky, A.S. Chromosome painting in Tragulidae facilitates the reconstruction of Ruminantia ancestral karyotype. Chromosome Res. 2011, 19, 531. [CrossRef] [PubMed]

36. Gallagher, D.S.; Davis, S.K.; De Donato, M.; Burzlaff, J.D.; Womack, J.E.; Taylor, J.F.; Kumamoto, A.T. A Molecular Cytogenetic Analysis of the Tribe Bovini (Artiodactyla: Bovidae: Bovinae) with an Emphasis on Sex Chromosome Morphology and NOR Distribution. Chromosome Res. 1999, 7, 481-492. [CrossRef] [PubMed]

37. Vozdova, M.; Fröhlich, J.; Kubickova, S.; Sebestova, H.; Rubes, J. Meiotic Recombination in the Giraffe (G. reticulata). Cytogenet. Genome Res. 2017, 152, 73-80. [CrossRef] [PubMed]

38. Eickbush, T.H.; Eickbush, D.G. Finely orchestrated movements: evolution of the ribosomal RNA genes. Genetics 2007, 175, 477-485. [CrossRef] [PubMed]

39. Raskina, O.; Barber, J.C.; Nevo, E.; Belyayev, A. Repetitive DNA and chromosomal rearrangements: speciation-related events in plant genomes. Cytogenet. Genome Res. 2008, 120, 351-357. [CrossRef] [PubMed]

40. Grozdanov, P.; Georgiev, O.; Karagyozov, L. Complete sequence of the 45-kb mouse ribosomal DNA repeat: analysis of the intergenic spacer. Genomics 2003, 82, 637-643. [CrossRef]

41. Solano, E.; Taylor, P.J.; Rautenbach, A.; Ropiquet, A.; Castiglia, R. Cryptic speciation and chromosomal repatterning in the South African climbing mice Dendromus (Rodentia, Nesomyidae). PLoS ONE 2014, 9, e88799. [CrossRef] [PubMed]

42. Proskuryakova, A.A.; Kulemzina, A.I.; Perelman, P.L.; Makunin, A.I.; Larkin, D.M.; Farré, M.; Kukekova, A.V.; Johnson, J.L.; Lemskaya, N.A.; Beklemisheva, V.R.; et al. X Chromosome Evolution in Cetartiodactyla. Genes 2017, 8, 216. [CrossRef] [PubMed] 
43. Srivastava, R.; Srivastava, R.; Ahn, S.H. The epigenetic pathways to ribosomal DNA silencing. Microbiol. Mol. Biol. Rev. 2016, 80, 545-563. [CrossRef] [PubMed]

44. Gottlieb, S.; Esposito, R.E. A new role for a yeast transcriptional silencer gene, SIR2, in regulation of recombination in ribosomal DNA. Cell 1989, 56, 771-776. [CrossRef]

45. Li, G.; Davis, B.W.; Raudsepp, T.; Wilkerson, A.J.P.; Mason, V.C.; Ferguson-Smith, M.; O’Brien, P.C.; Waters, P.D.; Murphy, W.J. Comparative analysis of mammalian Y chromosomes illuminates ancestral structure and lineage-specific evolution. Genome Res. 2013, 23, 1486-1495. [CrossRef] [PubMed] 